Japanese Psychological Research

1989, Vol. 31, No. 4, 179-189

\title{
Cognitive motivational processes mediated by achievement goal tendencies
}

\author{
TOSHIHIKO HAYAMIZU, ATSUSHI ITO AND KAZUHITO YOSHIZAKI \\ Department of Educational Psychology, Faculty of Education, Nagoya University, Chikusa-ku, Nagoya \\ $464-01$
}

\begin{abstract}
Cognitive motivational processes mediated by achievement goal tendencies were examined based on Dweck's model. To conduct this study, three instruments were constructed in order to measure achievement goal tendencies, conceptions of ability and effort, and learning behavior. These were administered to 182 junior high school students. As the first step of data analysis, factor analyses for three measures were conducted for each of the respective measurement. Concerning achievement goal tendencies, two kinds of performance goal tendencies were found in addition to learning goal tendency. Also, three conceptions of ability and effort were detected: effort centered, ability centered and ability-effort relativity conception. As for learning behavior, two factors were extracted: noncompetition-competition oriented learning and comprehension-rote oriented learning. Second, by using path analysis, a new motivational model composed of four levels was examined: conceptions of ability and effort $\rightarrow$ achievement goal tendencies $\rightarrow$ learning behavior $\rightarrow$ school achievement. Through this analysis, the characteristics of three achievement goal tendencies were revealed.
\end{abstract}

Key words: achievement goal tendencies, conceptions of ability and effort, learning behavior, school achievement, cognitive motivational processes.

Recent studies on motivation for learning have focused on a wide variety of cognitive-based processes. What is called achievement goal is considered as one of these processes, and refers to the reason why students choose to engage in academic tasks. For example, Maehr (1983) proposed four goals: task goal, ego goal, social solidarity goal, and extrinsic rewards goal. Also, Nicholls (1983) suggested three types or states of motivation: extrinsic involvement, ego-involvement, and task-involvement. In addition, Ames (1984) gave three goal structures as motivational systems: competitive, cooperative, and individualistic.

In summary of these studies, Dweck (1986) remaked that those goals appeared to fall into two classes: (a) learning goals, in which individuals seek to increase their competence, to understand or master something new, and (b) performance goals, in which individuals seek to gain favorable judgments or to avoid negative judgments of their competence. It is supposed that learning goals and performance goals lead to the so-called intrinsic motivation and extrinsic motivation, respectively. However, Dweck did not merely reaffirm such two kinds of motivation. She distinguished between them in subjective cognitions while other researchers did in objective stimulus and situations. On the basis of above definition, she considered that if a student had high confidence in his present ability, he / she would show an adaptive (mastery-oriented) pattern characterized by challenge seeking and high persistence in the face of obstacles, regardless of his/her achievement goal. On the contrary, if another student was not confident with his/her own ability, he/she would take action with a maladaptive (helpless) behavior pattern characterized by challenge avoidance and low persistence in the face of difficulty in a performance goal situation. But he / she would, on the other hand, show an adaptive behavior pattern under a learning goal situation.

Also, Dweck assumed that each achieve- 
ment goal was influenced by a theory of intelligence, which is rather similar to the conception of intelligence. The first theory, which she has called an "entity" theory, involves the belief that intelligence is a relatively stable trait. Children behaving in accordance with this theory tend to subscribe to the idea that they possess a fixed amount of intelligence, that this intelligence is displayed through performance, and that the outcomes or judg. ments indicate whether they are intelligent or not. The second theory, which she calls an "instrumental-incremental" theory, involves the belief that intelligence is increased through one's own instrumental behavior. Thus, entity theorists should adopt performance goals, while incremental-instrumental theorists should be more likely to choose learning goals.

In most of the studies that have been conducted thus far, learning versus performance goals were induced by experimental manipulations, in other words, they were regarded as variables dependent upon situations. It can, however, be supposed that all the students have already formed different achievement goals through their various learning experiences. In the present study, we give attention to what we have called achievement goal tendencies, which indicate individual differences rather than situational differences. Because the achievement goal tendencies as individual differences are more likely to be associated with teachers' actual individualized guidance to motivate each student than the achievement goals as situational differences.

We aim, then, at making a new scale to measure achievement goal tendencies that could be a key concept toward understanding student motivation for learning. Although our scale was constructed using a number of items that had a satisfactory amount of content validity, the content of the scale should be examined not only logically but also empirically. In observation of this, factorial validity will be investigated. Based on Dweck (1986), we presumed the scale would be composed of two factors: learning goal tendency and performance goal tendency.

Furthermore, as Dweck (1986) had suggested, achievement goals have not merely become a matter for discussion, but in addition, motivational processes (that is, the linkages of "theory of intelligence $\rightarrow$ goal orientation $\rightarrow$ behavior pattern "), have been the chief point of the matter. However, we have yet to see studies that have revealed the whole linkages of the components of learning motivation on evidence. Lack of such studies may be ascribed to the absence of instruments by which researchers measure the theory of intelligence and the behavioral pattern. Instead of referring to the concepts of "theory of intelligence" and "behavior pattern," we have substituted "the conception of ability and effort" and "learning behavior," respectively.

The conceptions of ability and effort involve a much broader meaning than does the theory of intelligence. The reason why "ability" was used in place of "intelligence" is simply because " ability" is more familiar to Japanese junior high school students as our subjects than "intelligence." Our construct, then, is different from Dweck's in the following points: (1) the conception of effort is added; (2) not only fixed or malleable characteristics of ability and effort but also various others are dealt with; (3) the relation between ability and effort is investigated. Because ability is closely related to effort in the actual learning situation, it is expected that manipulating the two together may provide more productive results. Several kinds of conceptions of ability and effort will be revealed through the result of a factor analysis and it is predicted that those are closely connected with some achicvement goal tendencies. With respect to behavior pattern, Dweck has focused upon only one perspective of achievement behavior, that 
is, mastery-oriented or helpless behavior. These behavioral differences are regarded as quantitative ones, e.g., the amount of challenge and persistence especially in cases of failure. However, we are concerned with qualitative differences of achievement behavior, regardless of success or failure. Especially, we have paid attention to the daily learning behavior as qualitative aspects of achievement behavior. With respect to our methodology, further, we intended to investigate the achievement behavior with an inquiry. If we had set a design to examine achievement behavior by an experimental method, we would have adopted their quantitative aspects in success or failure situations. Thereby, we believe here that the daily learning behavior is more suitable for knowing the qualitative differences of achievement behavior. Also, it is expected that measuring the differences of learning behavior may provide abundant and concrete information concerning motivational processes, probably because actual learning behavior is not as situation-specific and abstract as mastery or helpless behavior.

Naturally, we guess that students' motivation originating from achievement goal tendencies might reflect on their school achievement. That is, school achievement is a very important index of motivational outcomes. Nevertheless, Dweck has given us few suggestions about the relationship between motivational processes and school achievement. It appears that achievement goal tendencies have some influence on the latter. However, how and what achievement goal tendencies predict school achievement must be shown precisely. It can be questioned as to whether achievement goal tendencies influence school achievement directly or indirectly (mediated by learning behavior). We tried to wholly reveal the causal relationships in the motivational processes, which consist of: (1) conceptions of ability and effort; (2) achievement goal ten- dencies; (3) learning behavior and (4) school achievement, in order from antecedent to consequent variables. Our purpose of the present study can be summarized as follows; first, identifying what achievement goal tendencies junior high school students have; second, exploring as to whether the assumed causal linkages among four variables are valid for junior high school students.

\section{Method}

\section{Subjects}

The subjects were 251 junior high school students in the eighth grade (126 boys and 125 girls).

\section{Procedure}

The questionnaire was composed of three sets of measures. Items in each set were selected on the basis both of a preceding study (Hayamizu, 1987) and of a preliminary survey.

The first set was for the measurement of achievement goal tendencies and was composed of 26 five-point scale items, which were intended to express either the learning goal tendency or the performance goal tendency. Having the intention to measure general achievement goal tendencies, we avoided using items which had focused on any particular school subject. The instruction given to each subject was to indicate his/her reasons for learning at school or studying at home by circling one of the five alternative points on a scale, worded in the following manner: never, rarely, neither, sometimes, always. Some instances of the items were "I learn because I enjoy problem-solving," and "I learn because I wish to get better grades than my peers." (see Table 1)

The second set was constructed in order to measure conceptions of ability and effort. Selected 27 five-point scale items questioned the subjects about what they thought of ability, effort, and the rela- 
Table 1

Factor loadings of achievement goal tendencies after varimax rotation

\begin{tabular}{|c|c|c|c|c|}
\hline & I & II & III & $h^{2}$ \\
\hline I learn because I enjoy problem-solving. & .75 & -.03 & -.05 & .57 \\
\hline $\begin{array}{l}\text { I learn because I enjoy challenging difficult } \\
\text { things. }\end{array}$ & .78 & .14 & -.11 & .65 \\
\hline $\begin{array}{l}\text { I learn because I enjoy getting to know how } \\
\text { to solve problems. }\end{array}$ & .68 & .15 & .12 & .49 \\
\hline $\begin{array}{l}\text { I learn because I enjoy the process of gaining } \\
\text { ability. }\end{array}$ & .58 & .11 & .37 & .49 \\
\hline $\begin{array}{l}\text { I learn because I enjoy overcoming stumbling } \\
\text { blocks and failure. }\end{array}$ & .68 & .17 & .15 & .52 \\
\hline $\begin{array}{l}\text { I learn because I enjoy finding new means of } \\
\text { problem-solving. }\end{array}$ & .65 & .17 & .02 & .45 \\
\hline I learn because I can get to know new things. & .60 & .08 & .21 & .41 \\
\hline $\begin{array}{l}\text { I learn because I am pleased when I can solve } \\
\text { a difficult problem. }\end{array}$ & .64 & .28 & .14 & .52 \\
\hline I learn because I like to use my head. & .64 & .23 & -.03 & .46 \\
\hline $\begin{array}{l}\text { I learn because I want to be praised by my } \\
\text { parents and teachers. }\end{array}$ & .21 & .70 & .11 & .54 \\
\hline $\begin{array}{l}\text { I learn because I want to be noticed by my } \\
\text { parents and teachers. }\end{array}$ & .22 & .61 & .34 & .54 \\
\hline $\begin{array}{l}\text { I learn because I can be proud of obtaining } \\
\text { good grades. }\end{array}$ & .19 & .70 & .09 & .53 \\
\hline $\begin{array}{l}\text { I learn because I don't want to be scolded by } \\
\text { my parents and teachers. }\end{array}$ & -.20 & .60 & .12 & .41 \\
\hline $\begin{array}{l}\text { I learn because I don't want to be made a } \\
\text { fool of by my peers. }\end{array}$ & .09 & .62 & .21 & .44 \\
\hline $\begin{array}{l}\text { I learn because I want attention from my } \\
\text { peers. }\end{array}$ & .27 & .76 & -.01 & .64 \\
\hline $\begin{array}{l}\text { I learn because I feel satisfied when I outdo } \\
\text { my rivals. }\end{array}$ & .35 & .57 & .22 & .49 \\
\hline I learn because I want to get grades. & .00 & .31 & .64 & .51 \\
\hline $\begin{array}{l}\text { I learn because I don't want to fail in my } \\
\text { admission exmas. }\end{array}$ & -.02 & .21 & .67 & .49 \\
\hline $\begin{array}{l}\text { I learn because I wish to be admitted to a } \\
\text { reputable high school or university. }\end{array}$ & .07 & .26 & .64 & .49 \\
\hline $\begin{array}{l}\text { I learn because I wish to get good marks in } \\
\text { tests. }\end{array}$ & -.04 & .26 & .73 & .60 \\
\hline $\begin{array}{l}\text { I learn because I want to improve my aca- } \\
\text { demic ability. }\end{array}$ & .49 & -.12 & .50 & .51 \\
\hline $\begin{array}{l}\text { I learn because what knowledge I gain now } \\
\text { can be useful later. }\end{array}$ & .48 & -.09 & .41 & .41 \\
\hline I learn because I want to show my ability. & .48 & .36 & .26 & .43 \\
\hline $\begin{array}{l}\text { I learn because I enjoy discovering how much } \\
\text { my ability has improved. }\end{array}$ & .42 & .08 & .61 & .55 \\
\hline I learn because effort brings about ability. & .50 & -.01 & .58 & .59 \\
\hline $\begin{array}{l}\text { I learn because I wish to get better grades } \\
\text { than my peers. }\end{array}$ & .12 & .54 & .47 & .53 \\
\hline $\begin{array}{c}\text { contribution } \\
(\%)\end{array}$ & $\begin{array}{r}5.57 \\
(21.4)\end{array}$ & $\begin{array}{r}3.97 \\
(15.3)\end{array}$ & $\begin{array}{r}3.72 \\
(14.3)\end{array}$ & \\
\hline
\end{tabular}


tionship between them. Some of the items, for example, were "Ability is determined by nature," and "Ability can be improved through effort." The subjects were asked to indicate their degree of agreement for each item on a scale of one to five with the following wording: disagree, slightly disagree, neither, slightly agree, agree.

The third set of 15 bipolar items was devised for measuring learning behvaior. Each item had two contrasting statements, one of which was intended on representing the learning behavior of a student with a learning goal tendency and the other, that of a student with a performance goal tendency. The reason why we used two-pole scales is that we wanted to determine exactly which behavior of the two goal tendency types the student will tend to take. One of the items, for example, was "I like to grapple with applied problems" versus "I prefer problems that can be solved by rote." The subjects were asked to rate each statement so as to best represent their normal learning behavior. Each item consisted of five point scales with the opposite statements at the two poles.

Aside from the three measures stated above, we also obtained the students' school grades for five subjects: Japanese, social studies, mathematics, science and English. The grade of each subjects ranged from one to five, and we made use of the sum of these as an index of school achievement.

\section{Results}

\section{Factor Analyses of Three Measures}

Achievement goal tendencies. A factor analysis (principal factor with varimax rotation) of the achievement goal tendencies was conducted, and we found that the structure of achievement goal tendencies consisted of three factors, since there appeared to be an obvious break between the third factor's eigenvalue and that of the fourth factor. The cumulative percentage of variance accounted for by the three factors was $51 \%$. Items used for further analyses are shown in Table 1 with their factor loadings (more than .50) in italic type, and the rest are listed merely as residual items.

As can be seen in Table 1, the first factor was loaded by nine items, which can be thought of as expressing a learning goal tendency just as it had been conceptualized by Dweck (1986). We summed up the scores of these nine items and made a composite score as a scale of learning goal tendency ( $L G$ for short). The mean and the standard deviation of $L G$ were 24.52 and 6.83 , respectively. The Cronbach alpha reliability coefficient of this scale was calculated to be 87 .

The second factor included seven items while the third factor had four. Though the items in both factors could be regarded as indicating the performance goals suggested by Dweck (1986), the result obtained here shows that there could be two kinds of performance goal tendencies. All the items in the second factor express interpersonally oriented reasons for learning, that is, approval seeking and rejection avoidance. In other words, this factor represents the goal tendency of drawing out favorable judgments about one's achievement rather than that of increasing one's achievement. The items in the third factor clearly express the purpose for trying to gain higher achievement, including the perspective on one's future school background. The scores of seven items of the second factor, and four items of the third factor were also summed up separately to form two kinds of scales for performance goal tendencies. The former tendency was called $P \alpha G$ and the latter one was named $P \beta G$. The mean and the standard deviation of $P \alpha G$ were 18.66 and 5.65, and those of $P \beta G$ were 15.45 and 3.10 . The reliability coefficients of $P \alpha G$ and $P \beta G$ were .76 and .53 respectively. The correlations among the three scores were calculated to be as follows: .42 
between $L G$ and $P \alpha G ; .23$ between $L G$ and $P \beta G$; and .49 between $P \alpha G$ and $P \beta G$.

Conceptions of ability and effort. Similar to the analysis of achievement goal tendencies, a factor analysis of conceptions of ability and effort yielded three factors, with an apparent break between the eigenvalues of the third and the fourth factors. The cumulative percentage of variance accounted for by the three factors was $32 \%$. We selected 21 items with factor loadings of more than .40 while the remaining six items were regarded as residual.

The first factor was composed of 10 items, such as: "Even the hardest effort cannot be substituded for high ability,"; "A person with a lot of ability can do anything successfully,"; "The more talented one is, the less effort he needs," and "Ability is determined by nature." The composite score of these 10 items was taken as a scale for ability centered conception ( $A C$ for short).

The second factor was composed of seven items such as: "Ability can be improved through effort," ; A person with a lot of ability won't always be successful after going out into the world." and "Effort is one aspect of ability." The composite score of these items served as a scale of ability-effort relativity conception (AER for short).

The final factor consisted of four items such as: "A person who puts in effort into one subject endeavours in another subject," and "A person with a lot of ability is a man of great effort." The composite score in this case was intended to be called a scale of effort centered conception (EC for short).

The reliability coefficients of $A C, A E R$, and $E C$ were calculated to be $.75, .70$, and .44 , respectively.

Learning behavior. From a factor analysis of learning behavior, we extracted two factors. The criterion for adopting two factors was that there was a clear break between the eigenvalues of the second and the third factors. The percentage of cumulative proportion of variance was $30 \%$. We utilized 11 items with factor loadings more than .30 , while the rest were left as residual items.

The first factor contained five items, some of them were "I learn only for examinations vs. I learn irrespective of examinations," and "I learn hard in a competitive situation vs. I learn constantly whether if $I$ am alone or if $I$ am in competition with others." The composite score of this factor was called competition oriented vs. noncompetition oriented (COMNONCOM for short). In COM-NONCOM, the higher one's score was, the more he was noncompetitively oriented toward learning.

The second factor contained six items, some of which were: "I try to understand logically rather than attempt to learn by rote vs. I try to learn by rote what I can and cannot understand," and "I prefer problems that can be solved by applying what I've learned vs. I prefer problems that are quite similar to what I've just learned." We called the composite score of this second factor comprehension oriented vs. rote oriented (COMP-ROTE for short). Here the high score of a subject meant that he was more oriented to learning by rote.

The reliability coefficients of $C O M$ NONCOM and COMP-ROTE were .68 and .53 .

\section{Path Analysis for Causality}

It was assumed that the cognitive model was composed of four levels; " conceptions of ability and effort" $\rightarrow$ "achievement goal tendencies" $\rightarrow$ "learning behavior" $\rightarrow$ "school achievement." This model assumed no causal reciprocity within the same levels (i.e. among $L G, P \propto G$, and $P \beta G)$. In accordance with the model, path analysis was run in the following three steps. Figure 1 presents the results of total path analysis. 
Step 1. " conceptions of ability and cffort" $\rightarrow$ " achievement goal tendencies."

Multiple regression analysis was used to identify which of the three independent scales $(A C, A E R$, and $E C)$ were determinants for each of three achievement goal tendencies $(L G, P \alpha G$, and $P \beta G)$.

(1) Determinants of $L G . E C(\beta=.17$, $p<.01)$ and $A C(\beta=-.11, p<.08)$ had significant dependency on $L G$. The positive relationship between $E C$ and $L G$ showed that if the $E C$ level increases, so does the $L G$ level. The negative relatationship between $A C$ and $L G$ indicates that an increase in the $A C$ level results in a decrease in the $L G$ level.
(2) Determinants of $P \alpha G . E C(\beta=.11$, $p<.08)$ had a nearly significant dependence on $P \alpha G$ while the two other scales did not. This positive relationship suggests that as the $E C$ level increases, so does the $P \propto G$.

(3) Determinants of $P \beta G$. Only $A E R$ had a significant dependency on $P \beta G(\beta$ $=.17, p<.01)$ in the positive direction, suggesting that as the $A E R$ level increases, so does the $P \beta G$.

Step 2. "conceptions of ability and effort" $\rightarrow$ " achievement goal tendencies" $\rightarrow$ "learning behavior."

Multiple regression analysis was used to identify which of six independent scales

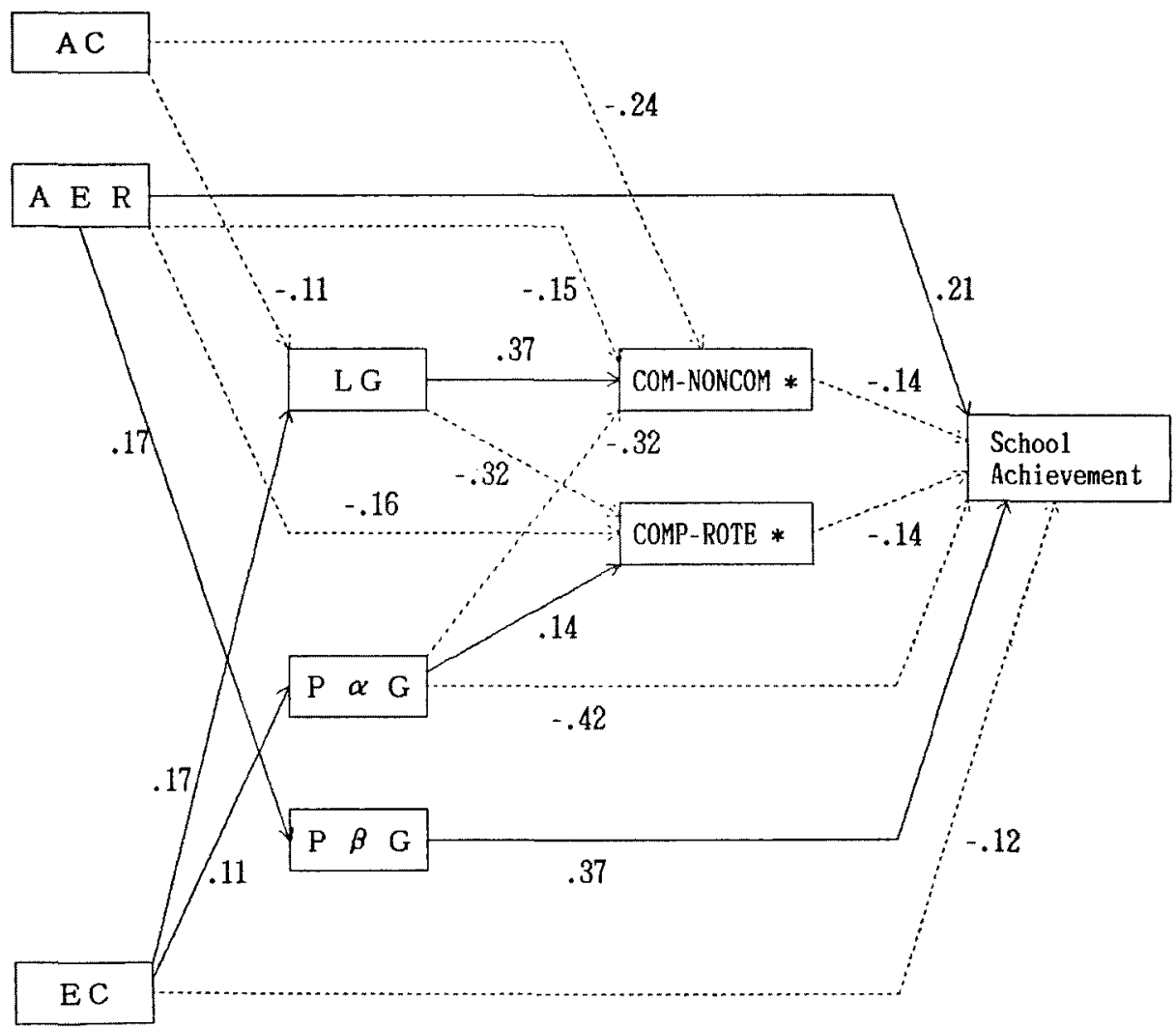

Fig. 1. Path diagrams of effects of conceptions of ability and effort, achievement goal tendencies, and learning behavior on subsequent school achievement.

Note: Solid lines and broken lines present positive and negative path, respectively.

* In the interpretation of all path coefficients directed at COM-NONCOM, the noncompetition orientation level was taken to be higher than the competition orientation one. Likewise, the same interpretation was done for comprehension versus rote orientation level, the latter being higher. 
$(A C, A E R, E C, L G, P \alpha G$, and $P \beta G)$ were determinants for each of two "learning behavior" scales (COM-NONCOM and COMP-ROTE).

(1) Determinants of COM-NONCOM. $A C \quad(\beta=-.24, p<.01), \quad L G(\beta=.37, p<$ $.001), P \alpha G(\beta=-.32, p<.01) A E R(\beta=$ $-.15, p<.05)$ had significant dependency on COM-NONCOM.

Two direct paths, from $A E R$ and $A C$, were found. These suggest increases in the $A E R$ and $A C$ levels are concurrent with a decrease in the noncompetition orientation level.

Three indirect paths were found; $A C$ $\rightarrow L G \rightarrow$ COM-NONCOM, EG $\rightarrow L G \rightarrow$ $C O M-N O N C O M$, and $E C \rightarrow P \alpha G \rightarrow C O M$ NONCOM. The first link suggests that concern about $A C$ reduces the $L G$ level, and as this $L G$ level increases, the noncompetition orientation level increases. The second link indicates that as the $E C$ level increases, so does the $L G$ level, subsequently reducing the competition orientation level. The final link suggests that as the $E C$ level increases, so does that of $P \alpha G$, while more concern about $P \alpha G$ reduces the noncompetition orientation level.

(2) Determinants of COMP-ROTE. AER $(\beta=-.16, p<.05), L G(\beta=-.32, p<.001)$, and $P \alpha G(\beta=.14, p<.07)$ had significant dependency on COMP-ROTE.

$A$ direct path from $A E R$ suggests that as the $A E R$ level increases, the rote orientation level decreases.

Three indirect paths were found: $A C \rightarrow$ $L G \rightarrow C O M P-R O T E, E C \rightarrow L G \rightarrow C O M P-$ $R O T E$, and $E C \rightarrow P \alpha G \rightarrow C O M P$-ROTE. The first link indicates that as the $A C$ level increases, the $L G$ level decreases, and less concern about $L G$ raises the rote orientation level. The second link suggests that as the $E C$ level increases, so does the $L G$ level, subsequently raising the comprehension orientation level. The final link suggests that as the $E C$ level increases, so does $P \propto G$, and as a consequence so does the rote orientation level.

Step 3. "conceptions of ability and effort" $\rightarrow$ " achievement goal tendencies" $\rightarrow$ "learning behavior" $\rightarrow$ "school achievement."

Multiple regression analysis was done to identify which of the eight independent scales $(A C, A E R, E C, L G, P \alpha G, P \beta G$, COM-NONCOM, and COMP-ROTE) were determinants for school achievement as a final analysis.

$A E R \quad(\beta=.21, p<.01), \quad E C \quad(\beta=-.12$, $p<.05), P \alpha G(\beta=-.42, p<.001), P \beta G$ $(\beta=.37, p<.001), \operatorname{COM}-\mathcal{N O N C O M}(\beta=-$ $.14, p<.05)$, and COMP-ROTE $(\beta=-.14$, $p<.05)$ had significant dependency on school achievement.

(1) "conceptions of ability and effort" $\rightarrow$ "school achievement." Two direct paths were found toward school achievement, one from $A E R$ and the other from $E C$. The former suggests that as the $A E R$ level increases, so does school achievement, while the latter suggests that as the $E C$ level increases, school achievement decreases.

(2) "achievement goal tendencies" $\rightarrow$ "school achievement." Two direct paths were found. The path from $P \alpha G$ suggests that as the $P \alpha G$ level increases, school achievement decreases, whereas the path from $P \beta G$ suggests that as the $P \beta G$ level increases, so does school achievement.

(3) "learning behavior" $\rightarrow$ "school achicvement." Interestingly, two paths from COMP-ROTE and COM-NONCOM were negative, showing that as the noncompetition orientation level and the rote orientation level increase, school achievement decreases.

(4) Indirect paths through four levels. Up to step 2, six indirect paths, " conceptions of ability and effort" $\rightarrow$ " achievement goal tendencies" $\rightarrow$ "learning behavior," were shown. As described above, both types of "learning behavior" had significant dependency on school achievement. Six indirect paths from "conceptions of ability and effort" to "school achievement" were indicated. 
Discussion

The factor analysis of achievement goal tendencies, contrary to our expectations, yielded three factors; two kinds of performance goal tendencies were found in addition to the learning goal tendency, which had close resemblance to Dweck's learning goals. The two kinds of performance goal tendencies were called $P \alpha G$ and $P \beta G . \quad P \alpha G$ is the tendency for students to learn in order to gain approval and to avoid refusal from their teachers and parents, whereas $P \beta G$ is the tendency for students to learn to achieve good grades and pass the admissions examinations. Though these may be equated to Dweck's performance goals (which were defined as achievement goals in order to gain favorable judgment or to avoid negative ones with respect to one's own competence), they include different properties on top of the ones similar to Dweck's. The first distinct feature is related to whose judgment (evaluation) is important for the students. High $P \alpha G$ students are concerned about judgment from others in regard to their own competence, whereas high $P \beta G$ students pay attention not only to those from others but also to self-judgment. In other words, we can assume the former students learn mainly to satisfy their social approval needs while the students do so to meet their achievement needs. A second feature is the difference in how far the achievement goal is located. That is, the latter's achievement goal is located further on the time dimension than that of the former. Probably, high $P \alpha G$ students will reduce their motivation immediately after they reach their goal (i.e. they are approved), whereas high $P \beta G$ students maintain their motivation at least until their success in their admissions examinations, even if they arrive at a sub-goal earlier (i.e. they achieve good grades in quizzes).

It was clearly found that these differences of goal characteristics had been re- flected on the diversity of associations between the conceptions of ability and effort, learning behavior and school achievement. Before considering these relations, contemplation on the assumed correspondence between the three conceptions of ability and effort extracted from the factor analysis and the two theories of intelligence derived from Dweck's logical analysis must be done. It seems to us that $A C$ is similar to her entity theory, but however, the former has a broader meaning than the latter. A student having $A C$ regards ability not only as being fixed but also as being universal. Both $A E R$ and $E C$ are close to her instrumental-incremental theory. However, there are subtle differences between these conceptions. It is for certain that $A E R$ assumes interaction between ability and effort (or the malleability of ability through effort) as well as $E C$, but $A E R$ does not entirely support the instrumentalincremental theory. As evidence, the students who were characterized by $A E R$ were aware of their limitations in their ability. They agreed to items such as: "A person has not only superior but also inferior ability to another," and "A person sometimes evaluates his / her own ability high while at other times low." On the contrary, $E C$ does not assume a limit of ability but does imply an infinite prospect due to effort. In other words, the students who harbor $E C$ are somewhat susceptible of over-estimating the potential consequences of their efforts.

While $P \alpha G$ was feebly dependent upon $E C, P \beta G$, on the other hand, was accelerated by $A E R$. According to Dweck, it was expected that both high $P \alpha G$ students and high $P \beta G$ students would regard their abilities as fixed. Therefore, the results were contradictory to her model. Why was a positive path from $E C$ to $P \alpha G$ shown? In this case, it appears that $E C$ includes a defensive connotation. That is, because the student is unlikely to recognize his / her low ability, he suppose that everything can be done through effort. 
Subsequently, it can be interpreted that defensive attitudes lead to seeking approval and avoiding refusal from others. Next, what about the positive path from $A E R$ to $P \beta G$ ? Unfortunately satisfactory explanations cannot be provided, but it is probable that the students who are realistic who take into consideration both the virtue of and the limit of ability and effort are likely to score higher on $P \beta G$, which is apparently the most realistic of all achievement goal tendencies.

Taking into regard the causal relations between achievement goal tendencies and learning behavior, the negative path from $P \alpha G$ to COM-NONCOM and the positive path from $P$ \& $G$ to COMP-ROTE were significant. That is, the high $P \propto G$ student preferred competition oriented and rote oriented learning situations more than did the low $P \alpha G$ student. Since performance goal oriented students aim at gaining evaluation of their own competence without necessarily enjoying the learning process, they like competitive learning situations in which they can seek a great deal of positive judgment from others, and they also use rote learning as a means when they have to acquire knowledge in spite of having little interest in the particular school subject. The results were consistent with Dweck's model.

On the other hand, $P \beta G$ had no significant path to learning behavior. This result seems to be incompatible with Dweck and what is regarded as common sense in education. It is inferred from the result that $P \beta G$ includes characteristics other than performance goal which Dweck had mentioned. As stated above, the high $P \beta G$ students want to get not only positive evaluation from others but also positive self-evaluation. The students can attain this even through the noncompetition oriented learning situation as well as that of competition oriented learning. Hence, $P \beta G$ did not predict COM-NONCOM. Also, there is another reason, namely, that both rote oriented learning and compre- hension oriented learning are indispensable for passing the examination, so each learning behavior is counterbalanced.

Interestingly, the significant paths from these achievement goal tendencies to school achievement were negative for $P \alpha G$ and positive for $P \beta G$. This result means that students who were likely to seek approval or to avoid refusal obtained poor school achievement, whereas those who learn to pass the examinations gained good grades. It can be interpreted that learning for concrete achievement objectives, established by themselves increases school achievement, but learning for the approval of others results in a decrease. Probably, high $P \alpha G$ students will stop learning as soon as they receive approval and they are not likely to presume responsiblity for their own learning. As can be seen from this, it should be noted here that we can find two kinds of performance goal oriented tendencies which have differing psychological functions from each other.

As for the discussion of $L G$, it appears that $L G$ is similar to the so-called intrinsic motivation. Two significant paths to $L G$ were found: a negative path from $A C$ and a positive path from $E C$. Since these conceptions are close to Dweck's entity theory and instrumental-incremental theory, respectively, the results support Dweck's hypothesis. The rejection of absolute ability and the acceptance of absolute effort make the students' intrinsic motivation increase because these beliefs bring about competent feelings toward their learning. Further, significant paths from $L G$ to learning behavior were obtained as expected. Since the students having high $L G$ did not intend to defeat others, and they enjoyed the learning process, they preferred noncompetition oriented learning to competition oriented learning. Also, they disliked rote learning because they did not aim at acquiring a lot of scrappy knowledge to increase school achievement.

To our surprise, however, a direct path 
from $L G$ to school achievement was not significant although a positive path was expected. Also, as indicated before, the preferences for the noncompetition oriented learning and comprehension oriented learning which were determined by $L G$ were negatively associated with school achievement. Until now, a great many educational psychologists have insisted that intrinsic motivation is the most appropriate for school learning amongst all of the kinds of learning motivation. However, as far as this research is concerned, $L G$ had no substantial effect on actual school achievement. High $L G$ students are so absorbed in their task that they will not memorize fragments of superficial knowledge in order to get good school grades. However, the means of grades of eight groups calculated through a mediancut of all the subjects into high and low groups for the $L G, P \alpha G$ and $P \beta G$ scores suggested that school achievement of the group of high $L G \times$ low $P \alpha G \times$ low $P \beta G$ was better than those of any other combinations. In other words, this indicates that a student having only a learning goal without having a performance goal may still attain good grades. Hence, it cannot be denied that $L G$ is a very important goal tendency. In addition, it is worth examining if the effect of the magnitude of $L G$ may or may not reflect upon other outcomes aside from school achievement, for example, contributive utterances in the class and active participation in school events. Also, tracing the student's course of development may be a way to detect other outcomes. High $L G$ students may be successful in their occupations after graduating from school.

From the results of the present study, a new cognitive-motivational process model composed of four levels can be proposed: "conceptions of ability and effort" $\rightarrow$ "achievement goal tendencies" $\rightarrow$ "learning behavior" $\rightarrow$ "school achievement."
The newly proposed model has more demonstrative evidence in the actual classroom than that of Dweck. This progress was greatly ascribed to our development of instruments for measuring achievement goal tendencies, conceptions of ability and effort and learning behavior. However, these measures must be further refined, for example, by adding new items to increase the reliability of each scale. As for learning behavior, by using objective methods, such a observation and teacher rating, it is neccessary to confirm the validity of the questionnaire and its findings. Furthermore, through the analysis of the data separated by sex, new insights may be led. Similarly, it would be interesting to investigate the motivational processes by focusing on each school subject separately in the future.

\section{References}

Ames, C. 1984 Competitive, comparative, and individualistic goal structures: A cognitivemotivational analysis. In R. Ames \& C. Ames (Eds.), Research on motivation in education. Vol. 1. New York: Academic Press. Pp. 177-208.

Dweck, C. S. 1986 Motivational processes affecting learning. American Psychologist, 41, 10401048.

Hayamizu, T. 1987 A study of motives for learning. Bulletin of the Faculty of Education, Nagoya University, 34, 15-23.

Maehr, M. L. 1983 On doing well in science: Why Johnny no longer excels, why Sarah never did. In S. G. Paris, G. M. Olson \& H.W. Stevenson (Eds.), Learning and motivation in the class-room. Hillsdale, NJ: Erlbaum. Pp. 179210 ,

Nicholls, J. G. 1983 Conceptions of ability and achievement motivation: A theory and its implications for education. In S. G. Paris, G. M. Olson \& H. W. Stevenson (Eds.), Learning and motivation in the class-room. Hillsdale, NJ: Erlbaum. Pp. 211-237.

(Received August 9, 1988; accepted March 11, 